\title{
Comprehensive Management of Infants with Gastroesophageal Reflux and Failure to Thrive
}

\author{
David R. Fleisher, MD
}

\section{Introduction}

Gastroesophageal reflux disease (GERD) in infants is defined as abnormal gastroesophageal reflux (GER) complicated by esophagitis, respiratory disease, or failure to gain weight. ${ }^{1}$ One of the most common forms of GERD reported in several large series of infants was abnormal GER with weight loss; many of these infants did not have esophagitis or respiratory complications..$^{2-8}$ It is generally assumed that failure to thrive in such infants is a complication of vomiting and loss of ingested nutrients. ${ }^{9,10}$ However, more than $20 \%$ of healthy infants thrive despite abnormal GER and frequent, often projectile, vomiting. ${ }^{1}$ Why is it that most infants with abnormal reflux gain weight normally and relatively few fail to thrive? ${ }^{11}$

An alternative hypothesis regarding vomiting and failure to thrive is that they may be coincidental; they may have different or common causes, but they may not be connected simply as primary and secondary phenomena. This hypothesis implies that optimal management requires evaluations of both the causes of the infant's vomiting and the causes of his or her failure to thrive without presuming that GER is the primary disease and failure to grow its complication. I would hypothesize further that in many infants, stress is a major

David R. Fleisher, MD, is Associate Professor of Clinical Child Health at the University of Missouri School of Medicine, Columbia. Curr Probl Pediatr 1995;25:247-53.

Copyright (c) 1995 by Mosby-Year Book, Inc.

$0045-9380 / 95 / \$ 6.00+.10 \quad \mathbf{5 3 / 1 / 6 7 4 1 2}$ pathogenic factor common to both vomiting and failure to thrive.

Stress and the Pathogenesis of Nonorganic Failure to Thrive

Almy ${ }^{12}$ defined emotional stress as "any situation regarded by an individual as a threat to his security." The perceived threat may be current or anticipated, realistic or unrealistic. This definition pertains to older children and adults. Emotional stress in infants, however, has to do with distress experienced in the dyadic relationship between infant and caregiver. ${ }^{13}$

A dyadic relationship is one in which influences flow in both directions. The mother gets to know, love, and nurture her infant. The infant begins to develop a sense of self, attachment, trust, and the ability to explore and manipulate his or her environment. ${ }^{14-19}$ The dyadic relationship may malfunction because of problems inherent to the infant, such as a regulatory disorder causing disturbances in his or her sensory, sensorimotor, or organizational processing ${ }^{20}$; a "mismatch" of the mother's and infant's temperaments; or the parents' disappointment in their expectations for their infant or themselves. ${ }^{21}$ In these cases, opportunities for mutual delight and satisfaction may be missed. The mother may experience feelings of rejection by or for her infant, which may then cause depression. Such conditions cause distress in the infant, which may result in the disturbances in eating, sleeping, and social interaction that are often found in infants who fail to thrive. ${ }^{22,23}$ 


\section{Stress and Vomiting}

Emotional stress affects the motility of the esophagus, ${ }^{24}$ antrum, ${ }^{25,26}$ small bowel, ${ }^{27-31}$ and colon. ${ }^{32} \mathrm{~A}$ recent study by McDonald-Hale et al. ${ }^{33}$ showed that relaxation training lessened GER in patients with GERD. Physiologic research by Holle et al..$^{34,35}$ showed that emptying of liquids from the canine stomach depends on synchrony between antral contraction and pyloric relaxation. Optimal conditions for gastric emptying are present an average of 10 seconds per minute during the 4 hours immediately after a meal. The coordination of antropyloric activity is influenced by a vagovagal reflex transmitted by the hepatopyloric and pyloric branches of the vagus nerve.

It is tempting to hypothesize that autonomically mediated incoordination caused by the infant's emotional state or level of arousal might induce slower gastric emptying and the more forceful or prolonged nonpropulsive antropyloric motility often seen in infants with "innocent vomiting" GER"1,37,38), "nervous vomiting," motility syndrome. ${ }^{39}$

Although evidence for the effects of emotions on gastrointestinal function seems incontrovertible, the emotional life of infants and the maternal-infant relationship are seldom mentioned in the pediatric literature on GER or the clinical management of vomiting babies. ${ }^{2-10,38-46}$ GER is measurable; conversely, aberrations in the mother-infant relationship are subtle, difficult to quantify, and require interpersonal rather than technologic diagnostic procedures. ${ }^{47}$ In contrast to the conventional approach to vomiting infants with failure to thrive (which focuses on data derived from esophageal $\mathrm{pH}$ monitoring and manometric, radiologic, and histologic data), cases have been reported of similar infants in whom elucidation of the nature and sources of stress was a principal focus of the diagnostic process. ${ }^{36,48,49}$ This alternative approach demonstrated that unrecognized and unrelieved stress can exacerbate functional and pathogenic GER and cause symptoms and signs that mimic organic diseases, such as pyloric stenosis and primary motility disorders. ${ }^{36,49}$ The usefulness of this alternative approach is exemplified by the following case.

\section{Case Report}

A boy weighing $3324 \mathrm{gm}$ was born at term to an 18-year-old primigravid mother and a 24-year-old father. The pediatrician instructed the parents to burp the infant after every ounce of formula "to prevent bellyaches." The infant was discharged at 2 days of age on feedings of Enfamil formula with low iron (Mead Johnson Nutrition, Evansville, Ind.). "Spitting up" began at 4 weeks. Fussiness became troublesome at 7 weeks. "He ate well, but he screamed as soon as I took the bottle out of his mouth," his mother said. Weight lag was noticed at 2 months. Vomiting became projectile. At 9 weeks, the pediatrician palpated an "olive tumor" and referred the patient to a pediatric surgeon for suspected pyloric stenosis.

The patient's first hospitalization lasted 1 week. Physical examination on admission did not confirm the presence of an olive tumor. Laboratory findings were serum sodium level, $140 \mathrm{mEq} / \mathrm{L}$; potassium, $5.4 \mathrm{mEq} /$ $\mathrm{L}$; chloride, $107 \mathrm{mEq} / \mathrm{L}$; and $\mathrm{CO}_{2}, 18 \mathrm{mEq} / \mathrm{L}$. An ultrasonographic reading was initially interpreted as showing pyloric wall thickness of $5 \mathrm{~mm}$. A laparotomy was performed in the patient within 2 hours of admission. No pyloric tumor or duodenal obstruction was found. A central venous catheter was inserted percutaneously. Parenteral nutrition was begun after surgery. The nasogastric tube was removed on the third hospital day. A barium study of the upper gastrointestinal tract on the fourth hospital day showed spontaneous GER to a level just above the thoracic inlet and "significant delay" in gastric emptying, but no obstruction. The patient was treated with intravenous metoclopramide, small oral feedings of a protein hydrolysate formula, and elevation of the head of his bed. He was placed on his abdomen or on his right side. Blood tests found no evidence of abnormal liver ı unction, hyperammonemia, or abnormal short-chain fatty acids. Results of a urine metabolic screen were negative. Nine diagnostic blood samples were drawn during the patient's hospital stay, and his hemoglobin progressively fell from 12.1 to $8.2 \mathrm{gm} / \mathrm{dl}$. Central venous feedings were tapered off by the sixth day, and limited oral feedings were advanced from $30 \mathrm{ml}$ to $90 \mathrm{ml}$ every 4 hours. The patient was given 39 injections of nalbuphine, including two on the day of discharge. (The mother believed that the nalbuphine given during the final 3 days was administered for fussiness caused by hunger rather than by pain.) The patient was discharged with feedings of Enfamil formula limited to $90 \mathrm{ml} \mathrm{ev}$ ery 4 hours and metoclopramide four times a day before feedings.

The patient's crying intensified at home. ("He drove me crazy with his screaming," his mother said.) His vomiting became more forceful; loose stools caused a bleeding diaper rash. A switch to Nutramigen formula (Mead Johnson Nutrition, Evansville, Ind.), 150 $\mathrm{ml}$ every 4 hours, and lowering the dose of metoclopramide did not help. The patient lost weight and was hospitalized at 3 months of age, 2 weeks after his previous discharge.

The second hospitalization lasted 3 days. Physical examination on admission showed a scrawny infant whose weight was below the 5 th percentile, length at 
the 10th percentile, and head circumference at the 25th percentile. He cried intensely and fed avidly, but physical findings were otherwise unremarkable. Laboratory studies were restricted to stool specimens, which were negative for enteric pathogens, Clostridium difficile toxin, and occult blood. A provisional diagnosis of nervous vomiting was made and a "therapeutic trial of comfort" was begun. ${ }^{36}$ The mother was encouraged by the possibility that her infant's intractable vomiting might not be the root cause of his weight loss and irritability. The safety and support afforded by the inpatient setting permitted us to test the premise that the infant's condition would deteriorate if he was fed and comforted as though he were entirely well. The baby was continued on the same formula he had been fed before admission, but he was fed whenever and as much as he wanted. Burping was done only when he paused during feedings. No metoclopramide or other medications were administered. Venipunctures and other uncomfortable procedures were omitted. The baby was promptly comforted when fussy and shielded as much as possible from environmental excitement during feedings and when put to sleep. He slept on a horizontal bed in whatever position he seemed to prefer. Most of the caregiving was done by his mother. His intake averaged 126 calories/ $\mathrm{kg}$ /day during the 2 full days he was in the hospital. His urine's specific gravity was 1.022 on admission and ranged between 1.003 and 1.011 thereafter. Nurses' notes recorded that he had "...multiple wet burps after every feeding, but no projectile emesis." He passed a total of six stools, which were of mushy and formed consistency. A diagnostic interview $^{50}$ of the mother revealed overwhelming distress and exhaustion, but no evidence of maternal rejection, abuse, or neglect. The patient gained an average of 105 gm per 24 hours. On the evening before discharge, nursing personnel noted that "the mother holds the baby lovingly...mother cuddles closely." The patient was discharged on a cow's milk formula with iron.

After discharge, the patient continued an accelerated weight gain trend except during a 2-day illness at $33 / 4$ months of age, which was accompanied by bloodflecked diarrhea of undetermined cause that subsided spontaneously. At $53 / 4$ months, the patient's weight was above the 10th percentile. He vomited less and had no signs of GERD (Figure 1).

\section{Comment}

This patient's vomiting conformed to the definition of nervous vomiting: vomiting that accompanies infant stress, impairment of maternal-infant reciprocity, and failure to thrive; the vomiting and failure to thrive remit after dysfunction in the nurturing relation-

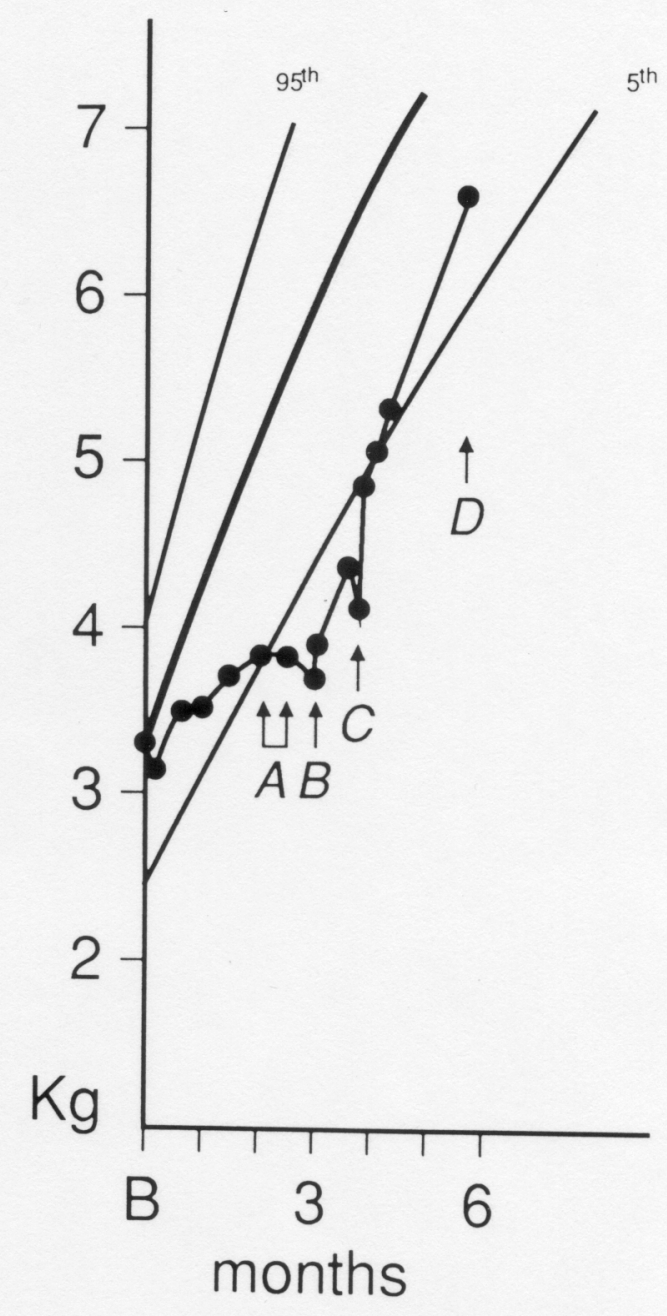

FIGURE 1 . The patient's weight course during his first hospitalization $(A)$, during his second hospitalization $(B)$, during his diarrheal illness $(C)$, and at time of follow-up (D).

ship resolves ${ }^{36}$ Nervous vomiting may be an extension of innocent vomiting, which occurs in $20 \%$ or more of well babies. Innocent vomiting is defined as excessive, functional GER without failure to thrive, esophagitis, respiratory complications, or dysfunction in the nurturing relationship; it resolves spontaneously by or before 18 months of age. ${ }^{1}$

The management of this patient before his second hospitalization exemplifies bias in the approach to understanding and remedying patients' illnesses. The focus was on the diseases that might be causing the patient's symptoms and not on the psychologic, social, and developmental factors that may have contributed to the clinical problem. At the very beginning of this patient's life, the pediatrician advised the mother to burp the baby after every ounce on the assumption that noneructated air causes abdominal pain. Apparently, no thought was given to the possibility that this warning might cause her to anticipate pain and burden her 
with the responsibility of preventing it. Such statements create concern and may damage the parents' self-confidence and optimism, which in turn may create "vulnerability" ${ }^{\prime 51}$ and impair thriving. ${ }^{52,53}$ No scientific proof exists that fussiness of the " 3 months' colic" type is caused by esophageal or abdominal pain or that the presumed abdominal pain is caused by aerophagia. ${ }^{54,55}$ When the patient became fussy, no thought was given to alternate hypotheses, for example, that the crying might have been due to the baby's inherent crying pattern ${ }^{56}$ the baby's temperament, ${ }^{57}$ the existence of a regulatory disorder, ${ }^{58}$ or that crying might have been exacerbated by the stress of the imposed feeding and burping regimen.

The occurrence and height of GER during radiographic examination of the upper gastrointestinal tract does not correlate with the severity of esophagitis, the extent of reflux found on esophageal $\mathrm{pH}$ monitoring, or responses to therapy. ${ }^{44}$ Nevertheless, it was assumed that the patient's weight lag was due to the GER seen during the barium study of the upper gastrointestinal tract. Pharmacologic, dietary, and positional measures were applied to remedy the reflux when the baby lost weight. The dysfunction in the maternal-infant relationship was considered to be secondary. The bias toward finding an organic cause for the vomiting and failure to thrive led to laparotomy, central venous feedings, nasogastric intubation, metoclopramide, and other components of standard medical management for GERD. ${ }^{1}$ The professionals " "blind spot" for the infant's stress was so opaque that behavior caused by hunger was misinterpreted as being caused by incisional pain and was treated with an intramuscular narcotic analgesic right up to the time of discharge from his first hospitalization.

\section{Biomedical and Biopsychosocial Models of Practice}

An underlying cause of the blind spot in the management of vomiting and failure to thrive lies in the generally unchallenged adherence to the biomedical model. ${ }^{59}$ This model implies that illness (the subjective distress that prompts patients to seek help from physicians $^{60}$ ) is caused by disease (demonstrable pathologic changes) and that the clinician's role is to relieve suffering by diagnosing and treating disease. ${ }^{61}$ Our patient's problems with vomiting and failure to thrive were reduced to a disorder involving the motility of tubes and sphincters and amenable to technologic measures. ${ }^{62}$ Such "reductionism" is avoided when the biopsychosocial model of care is applied. This model attempts to understand the infant, not only in terms of his or her GER, but also in terms of the circumstances in which it occurs, namely, the maternal-infant rela- tionship, the family, and its economic, social, and cultural milieu. Engel's biopsychosocial model fully acknowledges the great contributions made by science to our understanding of diseases and their treatment; however, it places a requirement on clinicians to manage the distress and suffering of patients by looking for all of the factors that may contribute to their illness. ${ }^{61}$ If the medical profession is to retain the goodwill and respect of its constituency, it must address the larger issue of "illness." ${ }^{60,63}$ This is especially important now in the face of enormous economic pressures to define illness in terms of codified diseases, diagnosis and treatment in terms of technical procedures, and physicians in terms of providers of same. ${ }^{64}$

\section{Medicine's Psychosocial Blind Spot}

How has medicine's psychosocial blind spot come about, and why is it so enduring? The answers to these questions may lie in the philosophic distinction between "essence" and "existence." "Essence," according to Rollo May, "refers to the greenness of this stick of wood,...its density, weight, and other characteristics which give it substance.... Western thought since the Renaissance has been concerned with essences.... The search for essences may indeed produce highly significant universal laws in science.... But, it can do this only by abstraction. The existence of the given individual thing has to be left out of the picture." ${ }^{65}$ An infant's existence, in contrast to his essential characteristics, refers to everything that is happening to him and in him, especially with respect to his developmental needs and their fulfillment within the mother-infant relationship. The task of the scientist is to study essential characteristics by isolating them from the infinite complexity (if not chaos) of existence. The task of the clinician is to cope with the realities of patients and their illnesses. The infant who vomits and fails to thrive cannot be managed optimally if the clinician's predominant focus is on abstract data derived from esophageal $\mathrm{pH}$ monitoring, gastric emptying studies, and other techniques while avoiding the realities of the infant's existence in a dyadic relationship with his or her caregiver. ${ }^{14,66^{*}}$ If we are unaware of the chasm between what is abstractly true and what is existentially real, then we are prone to confuse the practice of science and the practice of healing. This statement should not be taken as lessening the indispensability of science to clinical practice. Rather, it calls on clinicians to use science in the broader, more demanding task of enhancing well-being. If we restrict our purview to abstract data and concepts of disease, then management is impaired, as exemplified by the patient reported above. (A corollary stated by Rene Dubos is that the pursuit 
of science may be impaired when "the more measurable drives out the more important." ${ }^{\prime 67}$ ) In the biomedical model, the nature of a patient's illness is assumed to be composed of deviations from the norms of biologic variables. The alternative biopsychosocial model requires that the clinician analyze the meaning of the patient's history and physical and laboratory data in "psychological, social and cultural as well as anatomical, physiological or biochemical terms."

\section{Practical Considerations in Management}

Ideally, all infants who may have nonorganic failure to thrive, their caregivers, and the conditions of their lives should be evaluated by a team that includes a mental health professional skilled in infant psychiatry. ${ }^{20,47,68}$ Infant psychiatry is a relatively new field that encompasses diagnosis and treatment of disorders of mental health in children from birth to nursery school age, research in infant development, and developmental psychopathology. ${ }^{13-22,47,48,69}$ It has a burgeoning literature, including several textbooks $\mathrm{s}^{70-72}$ and a diagnostic manual. ${ }^{58}$ It offers a new dimension to the research in and treatment of infant vomiting disorders.

In reality, two obstacles are often encountered: (1) mental health clinicians with infant psychiatry skills may not exist in the community; and (2) even if such a resource were available, some parents may be unwilling to use it or unable to see the relevance of mental health issues to the baby's somatic symptoms. ${ }^{61}$ In such circumstances, the pediatrician or pediatric gastroenterologist can assess the importance of stress or dysfunction in the maternal-infant relationship by instituting a therapeutic trial of comfort ${ }^{36}$ as was done during the second hospitalization of the patient described above. This procedure requires concurrent efforts at relieving both the infant's and the parents' distress. Small, frequent feedings and imposition of arbitrary burping regimens are widely recommended for infants with GER. ${ }^{1,73,74}$ However, no data demonstrate improvements in vomiting, weight gain, or other benefits that outweigh the stresses created by repeated interruptions of feedings before satiation. ${ }^{75}$ When infants' stomachs become distended with air, they stop sucking. That is the time to apply burping maneuvers. Feeding during a therapeutic trial of comfort must aim not so much at controlling the vomiting as at "allaying the nervous unrest." ${ }^{176}$ Let infants eat as much and as often as they like, and let them vomit! ${ }^{36,48}$ Monitor their state of hydration and nutrition by accurately weighing them at least twice a day, measuring urine specific gravity with each voiding, and graphing the data so that they may be interpreted at a glance. Infants who vomit frequently and copiously may nevertheless develop a weight-gain trend after they begin to be fed in a more satisfying manner, especially if their feedings had been restricted or repeatedly interrupted previously.

The number and types of technical medical procedures necessary for diagnostic clarity are determined by the probability of organic causes and, equally important, by the infant's course after recognition and relief of physical and emotional discomfort. Concentrated diagnostic stress is avoided by minimizing the number of venipunctures and intervals during which feedings are withheld and by scheduling invasive procedures over several days. ${ }^{36}$

Weight-gain responses such as depicted in Figure 1 militate in favor of a functional rather than organic cause of vomiting, although both causes may coexist, even in infants who improve after they and their parents are made more comfortable. ${ }^{77}$

Both members of the dyadic relationship need to undergo healing. The mother must be respected; negative judgmental attitudes in hospital personnel poison the therapeutic trial by exacerbating the parents' irrational guilt for having "caused" their baby's illness. The ensuing adversarial feelings destroy collaborative effort aimed at finding the causes and remedies for the failure to thrive. Hospitalizing the infant often produces an improvement in the mother's mood and nurturing efforts because she is relieved of burdensome outside responsibilities and can focus all of her energies on satisfying and comforting her baby. She can also obtain the help of nursing and child care personnel for respite from the work of caring for her baby. Individual diagnostic/therapeutic interviews ${ }^{50}$ with each parent uncover the extent of maternal distress and family dysfunction, thereby helping them recognize and acknowledge the existing crisis and consider remedies. The mother's healing is enhanced as she observes the improvement in her baby's weight and learns that diagnostic tests show the absence of organic disease. Primary GER without esophagitis or respiratory complications is best viewed as physiologic rather than pathologic, previous weight loss notwithstanding; its prognosis should be viewed as excellent. The infant's vomiting must cease to cause anxiety and frustration in the parents. This attitudinal change is reinforced by the demonstration that their infant improves, rather than deteriorates, when previous antireflux measures are discontinued within the safety of the hospital.

\section{Conclusion}

Optimal management of infant vomiting requires more than demonstrating the presence of abnormal GER and applying antireflux techniques. It also requires comprehensive assessment of the infant and family who 
seek medical help for it. Current management of vomiting infants who fail to thrive lacks a psychosocial dimension and may therefore result in nontherapeutic or countertherapeutic outcomes. The importance of the psychosocial dimension has not been tested because of its de facto exclusion from the definitions of vomiting disorders based on GER data. This article briefly attempts to integrate gastroesophageal physiology, infant psychiatry, clinical process theory, and its philosophic underpinnings in putting forward a more comprehensive approach to infants who vomit and fail to thrive.

\section{References}

1. Boyle JT. Gastroesophageal reflux in the pediatric patient. Gastroenterol Clin North Am 1989;18:315-37.

2. Leape LL, Ramenofsky ML. Surgical treatment of gastroesophageal reflux in children. Arch Pediatr Adolesc Med 1980;134:9358.

3. Vos A, Borema I. Surgical treatment of gastroesophageal reflux in infants and children. J Pediatr Surg 1971;6:101-11.

4. Ferry GD, Selby M, Pietro TJ. Clinical response to short-term nasogastric feeding in infants with gastroesophageal reflux and growth failure. J Pediatr Gastroenterol Nutr 1983;2:57-61.

5. Kibel MA. Gastroesophageal reflux and failure to thrive in infancy. In: Gellis SS, editor. Gastroesophageal reflux. Report of the 76th Ross Conference on Pediatric Research; 1978 Mar 19-22; Carefree, Ariz. Columbus, Ohio: Ross Laboratories, 1978:39-47.

6. Ashcraft KW. Selection of patients for surgery. In: Gastroesophageal reflux. Report of the 76th Ross Conference on Pediatric Research. 1978:112-22.

7. Sondheimer JM, Mintz HL, Michaels M. Bethanechol treatment of gastroesophageal reflux in infants. J Pediatr 1984;104:128-31.

8. Tunell WP. Gastroesophageal reflux in childhood. Pediatr Ann 1989;18:192-6.

9. Balistreri WF, Farrell MK. Gastroesophageal reflux in infants. N Engl J Med 1983;309:790-2.

10. Markowitz JF. Disorders of upper gastrointestinal motility in infants and children. Prac Gastroenterol 1989;13(2):24-30.

11. Wood BSB, Astley R. Vomiting of uncertain origin in young infants. Arch Dis Child 1952;27:562-8.

12. Almy TP. The gastrointestinal tract in man under stress. In: Sleisenger MH, Fordtran JS, editors. Gastrointestinal disease. 2nd ed. Philadelphia: Saunders, 1978:3.

13. Seifer R, Dickstein S. Parental mental illness and infant development. In: Zeanah $\mathrm{CH}$, editor. Handbook of infant mental health. New York: Guilford Press, 1993:120-42.

14. Lewis M, Lee-Painter S. An interactional approach to the motherinfant dyad. In: Lewis M, Rosenblum LA, editors. The effect of the infant on its caregiver. New York: Wiley \& Sons, 1974:21-48.

15. Dunn J. Distress and comfort. Cambridge, Mass.: Harvard University Press, 1977.

16. Stern DN. The first relationship — infant and mother. Cambridge, Mass.: Harvard University Press, 1977.

17. Stern DN. The interpersonal world of the infant. New York: Basic Books, 1985.

18. Als $\mathrm{H}$. The unfolding of behavioral organization in the face of a biological violation. In: Tronick EZ, editor. Social interchange in infancy. Baltimore: University Park Press, 1982:125-60.

19. Brazelton TB. Joint regulation of neonate-parent behavior. In: Tronick EZ, editor. Social interchange in infancy. Baltimore: University Park Press, 1982:7-22.

20. Greenspan S, Wieder S. Regulatory disorders. In: Zeanah C, edi- tor. Handbook of infant mental health. New York: Guilford Press, 1993:280-90.

21. Levy R. Mother-infant relations in the feeding situation. In: Lebenthal E, editor. Textbook of gastroenterology and nutrition in infancy. New York: Raven Press, 1981:633-44.

22. Kreisler L, Cramer B. Infant psychopathology. In: Call JD, Galenson E, Tyson RL, editors. Frontiers of infant psychiatry. New York: Basic Books, 1983:129-35.

23. Berwick DM. Nonorganic failure-to-thrive. Pediatr Rev 1980;1:265-70

24. Anderson $\mathrm{KO}$, Dalton $\mathrm{CB}$, Laurence $\mathrm{AB}$, Richter JE. Stress induces alteration of esophageal pressures in healthy volunteers and non-cardiac chest pain patients. Dig Dis Sci 1989;34:83-91.

25. Stanghellini V, Malagelada JR, Zinsmeister AR, et al. Stress-induced gastroduodenal motor disturbances in humans. Gastroenterology 1983;85:83-91.

26. McCann MJ, Rogers RC. Central modulation of the vagovagal reflex: influence on gastric function. In: Tache $Y$, Wingate $D$, editors. Brain-gut interactions. Boca Raton, Fla.: CRC Press, 1991:57-69.

27. McRae S, Younger K, Thompson DG, et al. Sustained mental stress alters human jejunal motor activity. Gut 1982;23:404-9.

28. Cann PA, Reed NW, Cammack J, et al. Psychological stress and the passage of a standard meal through the stomach and small intestine in man. Gut 1983;24:236-40.

29. Kellow JE, Langeluddecke PM, Eckersley GM, Jones MP, Tennant CC. Effects of acute psychologic stress on small intestinal motility in health and the irritable bowel syndrome. Scand J Gastroenterol 1992;27:53-8.

30. Goin LS. Some obscure factors in the production of unusual small bowel patterns. Radiology 1952;59:177-84.

31. Friedman J. Roentgen studies of the effects on the small intestine from emotional disturbances. American Journal of Roentgenology, Radium Therapy, and Nuclear Medicine 1954;72:36779.

32. Wolff HG. Stress and disease. Springfield, Ill.: Charles C. Thomas, 1953:52-3.

33. McDonald-Hale J, Bradley LA, Bailey MA, et al. Relaxation training reduces symptom reports and acid exposure in patients with gastroesophageal reflux disease. Gastroenterology 1994;107:619 .

34. Holle GE, Hahn D, Forth W. Innervation of pylorus in control of motility and gastric emptying. Am J Physiol 1992;263:G161-8.

35. Holle GE, Steinbach E, Forth W. Intrinsic corporoantropyloric coordination of motility and gastric emptying. Am J Physiol 1994;266:G255-62.

36. Fleisher DR. Functional vomiting disorders in infancy: innocent vomiting, nervous vomiting and infant rumination syndrome. J Pediatr 1994;125(6 Pt 2):84-94

37. Jolley S, Herbst J, Johnson D, et al. Patterns of postcibal gastroesophageal reflux in symptomatic infants. Am J Surg 1979;138:946-50

38. Hillemeier AC, Lang R, McCallum R, et al. Delayed gastric emptying in infants with gastroesophageal reflux. I Pediatr 1981;98:190-3.

39. Byrne WJ, Kangarloo H, Ament ME, et al. Antral dysmotility: an unrecognized cause of chronic vomiting during infancy. Ann Surg 1981;193:521-4.

40. Herbst J, Meyers W. Gastroesophageal reflux in children. Adv Pediatr 1981;28:159-86.

41. Curci M, Dibbins A. Gastroesophageal reflux in children. Am J Surg 1982;143:413-6.

42. Swischuk L, Tyson K. "Burned-out" pyloric stenosis: an elusive gastric outlet obstruction. Radiology 1975;117:373-9.

43. Fonkalsrud E, Foglia R, Ament M, et al. Operative treatment for 
the gastroesophageal reflux syndrome in children. J Pediatr Surg $1989 ; 24: 525-9$

44. Sondheimer J. Gastroesophageal reflux: an update on pathogenesis and diagnosis. Pediatr Clin North Am 1988;35:103-16.

45. Orenstein S. Controversies in pediatric gastroesophageal reflux. J Pediatr Gastroenterol Nutr 1992;14:338-48.

46. Orenstein S. Gastroesophageal reflux. In: Hyman PE, DiLorenzo C, editors. Pediatric gastrointestinal motility disorders. New York: Academy Professional Information Services, 1994:55-88.

47. Hirschberg L. Clinical interviews with infants and their families. In: Zeanah C, editor. Handbook of infant mental health. New York: Guilford Press, 1993:173-90.

48. Ferholt J, Provence S. Diagnosis and treatment of an infant with psychophysiological vomiting. Psychoanal Study Child 1976;31:439-59.

49. Fleisher D. Infant rumination syndrome. Arch Pediatr Adolesc Med 1979;133:266-9.

50. Green M. Interviewing. In: Green M, Haggerty RJ, editors. Ambulatory pediatrics II. Philadelphia: Saunders, 1977:441-53.

51. Green M, Solnit A. Reactions to the threatened loss of a child: a vulnerable child syndrome. Pediatrics 1964;34:58-66.

52. Barbero G, Shaheen E. Environmental failure to thrive. J Pediatr 1967;71:639-44.

53. Altemeier WA, O'Connor S, Sherrod KB, et al. Prospective study of antecedents for nonorganic failure to thrive. J Pediatr 1985;106:360-5.

54. Barr RG. Colic and gas. In: Walker WA, Durie PR, Hamilton JR, Walker-Smith JA, Watkins JB, editors. Pediatric gastrointestinal disease. Philadelphia: BC Decker, 1991:55-61.

55. Barr RG. Normality: a clinically useless concept; the case of infant crying and colic. J Dev Behav Pediatr 1993;14:264-70.

56. Brazelton TB. Crying in infancy. Pediatrics 1962;29:579-88.

57. Carey WB. "Colic": primary excessive crying as an infant-environment interaction. Pediatr Clin North Am 1984;31:993-1005.

58. Wieder S, editor. Diagnostic classification: 0-3. Arlington, Va.: National Center for Clinical Infant Programs, 1994:31-8.

59. Engel GL. The need for a new medical model: a challenge for biomedicine. Science 1977;196:129-35.

60. Ford CV. The somatizing disorders. New York: Elsevier, 1983:8-13.

61. Fleisher DR. Integration of biomedical and psychosocial man- agement. In: Hyman PE, DiLorenzo C, editors. Pediatric gastrointestinal motility disorders. New York: Academy Professional Information Services, 1994:13-31.

62. Engel GM. "The best and the brightest": the missing dimension in medical education. Pharos 1973;36:129-33.

63. Engel GM. The clinical application of the biopsychosocial model. Am J Psychiatry 1980;13:535-44.

64. Annas GJ. Reframing the debate on health care reform by replacing our metaphors. N Engl J Med 1995;332:744-7.

65. May R. The origins and significance of the existentialist movement in psychology. In: May R, Angel E, Ellenberger HF, editors. Existence. New York: Basic Books, 1958:13.

66. Brazelton TB, Koslowski B, Main M. The origins of reciprocity: the early mother-infant interaction. In: Lewis M, Rosenblum LA, editors. The effect of the infant on its caregiver. New York: Wiley \& Sons, 1974:49-76.

67. Rogers DE. The doctor himself must become the treatment. Pharos 1974;37:124-9.

68. Benoit D. Failure to thrive and feeding disorders. In: Zeanah C, editor. Handbook of infant mental health. New York: Guilford Press, 1993:317-31.

69. Trad PV. Infant depression. New York: Springer-Verlag, 1986.

70. Rexford EN, Sander LW, Shapiro T, editors. Infant psychiatry. New Haven, Conn.: Yale University Press, 1976.

71. Call JD, Galenson E, Tyson RL, editors. Frontiers of infant psychiatry. New York: Basic Books, 1983.

72. Zeanah $\mathrm{CH}$, editor. Handbook of infant mental health. New York: Guilford Press, 1993.

73. Hillemeier AC. Reflux and esophagitis. In: Walker WA, Durie PR, Hamilton JR, Walker-Smith JA, Watkins JB, editors. Pediatric gastrointestinal disease. Philadelphia: BC Decker, 1991:417.

74. Gryboski J, Walker WA. Gastrointestinal problems in the infant. 2nd ed. Philadelphia: Saunders, 1983:36.

75. Wood B. Underfeeding as a factor in infantile vomiting. Lancet 1952;1:28-30.

76. Cameron HC. Some forms of habitual vomiting in infancy. BMJ 1925;1:872-6.

77. Gonzalez-Heydrick J, Kerner J, Steiner H. Testing the psychogenic vomiting diagnosis. Arch Pediatr Adolesc Med 1991;145:913-6. 